\title{
Risk factors and impact of stigma on psychiatric patients in Sohag
}

\author{
Taher Abdelraheem Sayed ${ }^{1}$, Magda Mohamed Ali² and Saber Hadad ${ }^{1 *}$
}

\begin{abstract}
Background: Stigma among psychiatric patients is pervasive all over the world. Our aim in this study was to investigate risk factors for stigma related to psychiatric disorders and to demonstrate the major consequences of mental stigma for patients who experience mental illness. We conducted a cross-sectional study and applied a stigma scale to 573 patients with psychiatric disorders who attended our outpatient psychiatry clinic. Participants were divided into two groups, group I (no.262) with low stigma score and group II (no.311) with high stigma score. The two groups were compared in term of socio-demographic characteristics (age, gender, level of education, residency, marital status, employment and socioeconomic level), factors related to the psychiatric disorder (duration of illness, number of psychiatric hospital admission and diagnosis) and impact of psychiatric illness (follow-up visits, adherence to medications and suicidal thoughts or attempts).

Results: The mean age of patients with high stigma score (group II) was $29 \pm 6$ years. High stigma score was more common in females (53.7\%), illiterate (11.9\%), living in rural areas (58.2\%), single (22.83\%), unemployed (44.37\%) and low socioeconomic class (59.49\%). Patients with a high stigma score showed longer duration of psychiatric disorder (43 \pm 8 months), more frequent number of psychiatric hospital admission (4.3 \pm 0.5$)$ and schizophrenia ((11.25\%) and other psychotic disorders (6.49\%) were common diagnoses. Patients with a high stigma score show poor adherence to medication (47.91\%) and follow-up (44.05\%) and a high frequency of suicidal ideation or attempt (47.91\%). Significant risk factors predicting high mental stigma were level of education (explaining about $23 \%$ of the risk, $P=0.03$ ), duration of mental illness (explaining about $25 \%$ of the risk, $P=0.019$ ), number of hospital admissions (explaining about $22.7 \%$ of the risk, $P=0.032$ ), diagnosis of mental illness (explaining about $27.7 \%$ of the risk, $P=0.01$ ).

Conclusion: Mental stigma is more prevalent among young aged individuals, females, single, unemployed, living in rural areas and those with lower educational and socioeconomic level. Mental stigma has a parallel correlation with psychiatric disorder duration, number of psychiatric hospital admissions, as well as diagnosis of psychotic disorder. The stigma of mental illness from the viewpoint of the patient may lead to delaying the access to care as well as poor adherence to medications and follow-up. Anti-stigma measures can contribute to diminishing the psychiatric illness effect.
\end{abstract}

Keywords: Risk factors, Mental, Stigma, Impact

\footnotetext{
*Correspondence: dr_hadad201444@yahoo.com

1 Department of Neuropsychiatry, Sohag Faculty of Medicine, Sohag University, Sohag, Egypt

Full list of author information is available at the end of the article
}

\begin{abstract}
Background
Most societies still have attitudes towards psychiatric symptoms that they consider these patients uncomfortable and threatening, this usually leads to stigma and discrimination against psychiatric patients [1]. Most patients who experience serious psychiatric illness face several challenges. The first challenge is the disability as well as the symptoms caused by the disorder, whereas
\end{abstract}


the second challenge is the prejudice and discrimination from society due to misbeliefs about psychiatric illness. Due to these challenges, patients typically have difficulty finding a suitable job, good housing or adequate health care [2].

Many psychiatric patients report that they experience stigma and related prejudice due to their illness as much as they experience stigma and prejudice against the symptoms of the disorder itself [3].

The stigma of mental illness is described as the devaluation, humiliation, and nuisance of people with mental illnesses [4]. In fact, stigma and prejudice have significant negative psychological, political, economic as well as social consequences for individuals with mental illnesses [5].

Stigma has a dual effect, public stigma as well as selfstigma. Public stigma is the reaction that the general public has to mentally ill patients, whereas self-stigma is the prejudice that mentally ill individuals turn against themselves. Moreover, public stigma is defined as a negative belief about a group of people, such as inadequacy and dangerousness, and then a negative emotional reaction after that agreement, like fear and anger. After that, they perform a behavior response to this agreement such as avoidance, withholding of employment and housing opportunities or withholding of assistance. In contrast, self-stigma is a negative belief related to oneself, for instance inadequacy or weak character, as well as approval of that belief and a negative emotional reaction (low self-efficacy and low self-esteem) followed by a behavioral reaction to this approval such as failure to pursue work or housing opportunities [2].

Beliefs and thoughts about the self are deeply shaped through the way we think others perceive it and an individual's self-concept is socially formed. Therefore, negative judgments from other people are usually incorporated into self-concept [6]. Self-stigmatization is a three-stage process in which an individual assigns to himself/herself a sign of social disability, internalize it, and presumes that others will act in a negative way towards him/her, or disesteem him/her [7]. Elevated rates of self-stigmatization are correlated with elevated rates of generalized mental illness, social anxiety, increased depression rates, low self-esteem, lower hopefulness, poor social, occupational functioning, poor treatment outcomes, absence of social support as well as the absence of cooperation during treatment, and finally the low quality of life [8].

Recent European studies have demonstrated that the pervasiveness of self-stigmatizing attitudes in people who experience extreme mental illness ranges from 36 to $42 \%$ [9]. Stigmatization in mental illness is likely to be similar in different societies [10]. World Psychiatry have illustrated that approximately $40-50 \%$ of schizophrenic patients suffer from a sense of shame due to the disorder [11].

To study the effect of stigma of mental illness and anti-stigma measures in Asian societies, Zhang et al., in 2019 conducted a large systemic review on existing research in six Asian societies (China, Hong Kong, Japan, Singapore, Korea, and Thailand); they concluded the following main findings, firstly, mentally ill patients are seen as dangerous and aggressive, especially those suffering from schizophrenia and bipolar disorder; second, psychiatric disorders are less accepted and considered as weakness in personality; third, families of mentally ill patients suffered from pervasive family stigma; fourth, there are more initiatives to decrease stigma of mental illness and there is attitude to treat psychiatric disorders in the community and the role of supernatural and religious approaches was decreasing [12].

There are several factors that may negatively impact psychiatric patients' quality of life like age, the intensity of mental illness, frequency of psychiatric hospitalizations, social anxiety, comorbidity with depression, poor or no partnership, low education as well as low selfesteem [13]. Mental illness stigma has many negative consequences such as poor prognosis [14], social isolation, low self-esteem [15], delaying or preventing seeking medical help [16] as well as suicidal thoughts [17].

Arab families view the experience of taking care of a mentally ill family member with embarrassment, loss, fear, and tingling of reputation of the family [18].

\section{Methods}

\section{Aim of the study}

Our aim in this study is to investigate correlates and risk factors for stigma related to psychiatric disorders and to demonstrate the major consequences of mental stigma for patients who experience mental illness.

This cross-sectional study was performed between April 2019 and October 2019 on 573 patients with mental illness who attended our outpatient psychiatric clinic. Local ethics committee approved the study protocol.

Participants were constructed about the study as well as its objectives, and then invited to participate. Written informed consent was obtained from patients for participation in this study. Exclusion criteria was applied to patients who refused to provide a written consent or provided an incomplete interview.

Inclusion criteria were as follows: Subjects between 18 and 65 years, diagnosed with mental disorder based on the Diagnostic and Statistical Manual of Mental Disorders, Fifth Edition (DSM-5). 
Exclusion criteria were as follows: Presence of a severe physical illness, intellectual disability, or organic mental disorder. We did not include addiction patients.

Patients completed a stigma scale questionnaire which is self-report scale of mental illness stigmatization that can be finished between 5 to $10 \mathrm{~min}$ and aids to comprehend more about the contribution of stigma to mental illness to research as well as clinical settings. Subjects expressed their agreement or disagreement with each of the 42 items on a five-point Likert scale that ranges from 'Strongly agree' to 'Strongly disagree' [19]. Then patients were divided into 2 groups; group I (no.262) who recorded less than 0.4 (converted score) which is considered a low stigma score and group II (no.311) who recorded 0.4 or more on the stigma scale, which is considered a high stigma score. The two groups were compared with regard to socio-demographic data, duration of mental illness, history of psychiatric hospital admission and psychiatric diagnosis. To identify the impact of the psychiatric stigma, the two groups were compared in terms of regular follow-up visits in psychiatric clinic (each patient has a follow-up file in our clinic and comes every month to take free medications; follow-up visits are considered irregular if the patient missed 3 or more visits in a year), adherence to psychiatric medication (assessed by direct asking of the patients and relatives if they stopped, changed the doses or the timing of the medications since last follow-up visit) and suicidal thoughts or attempts.

\section{Statistical analysis}

We used SPSS software (version 16.0; SPSS Inc., released 2007, Chicago, IL, USA) to analyze the data. In descriptive statistics, we presented quantitative data in the form of mean and standard deviation (SD), while qualitative data were presented in the form of frequencies and percentages. The mean values were compared using independent sample $t$ tests after assessment of normality of distribution. Qualitative variables were compared by Mann-Whitney $U$ test. We used cross-tabulation and Chi-square test for independence to assess the impact of stigma on suicide attempts, regularity of follow-up visits and adherence to medications. Multiple regression analysis was done to determine risk factors predicting mental stigma. $P$ value $<0.05$ is considered statistically significant.

\section{Results}

As shown in Table 1; high stigma score is found in younger, females, single, illiterate, unemployed patients and in those with low socioeconomic status or living in rural areas.
As shown in Table 2; Patients with high stigma score (group II) had significantly longer duration of illness measured in months ( $43 \pm 8$ vs $37 \pm 9$ ), more frequent psychiatric hospital admissions $(4.3 \pm 0.5$ vs $2.1 \pm 0.3)$ and had diagnosis of schizophrenia or other psychotic disorders.

As shown in Table 3; Patients with high stigma score had less regular follow-up visits, less adherence to medications and more frequent suicidal ideations or attempts than patients with low stigma score.

As shown in Table 4; significant risk factors predicting high mental stigma are level of education (explaining about $23 \%$ of the risk, $P=0.03$ ), duration of mental illness (explaining about $25 \%$ of the risk, $P=0.019$ ), number of hospital admissions (explaining about $22.7 \%$ of the risk, $P=0.032$ ), diagnosis of mental illness ( explaining about $27.7 \%$ of the risk, $P=0.01$ ).

\section{Discussion}

Mental illness stigma is still a worldwide psychiatric problem. Effective therapy for mental disorders can be obtained; however, there are several obstacles such as stigmatization against mentally ill patients that prevent them from obtaining the help they need to get better [20].

There are very limited studies performed in Upper Egypt that investigated the stigma of mental illness and its prevalence.

The current results revealed that there is a high prevalence of mental stigma among young patients (24 \pm 5 years) consistent with the results of Hartini et al. [21] who found that the mean age of mental stigma is 23.3 years. This can explained by the fear of mental stigma affecting future career as well as the future marriage of young psychiatric patients studying, and conversely, when people age, they become more indulgent of their illness and its related issues. Our results are in contrast to the results of Zaske et al. [22] who postulated that elevated stigma experiences are associated with aging.

The findings of the current research suggest that female psychiatric patients $(53.7 \%)$ reported a higher stigma score than male psychiatric patients $(46.3 \%)$ which is consistent with the findings of Boge et al. [23] and Kinson et al. [24] who stated that female subjects displayed elevated perceived stigma levels than males and demonstrated that elevated perceived stigma levels of among female subjects could be due to cultural norms as well as female contributions to the family or the social system. Mental stigma is most common in females and can be explained by excessive anxiety as well as fear of being labeled mentally ill, thus losing her opportunity to get married or to find a job. In contrast, Gierk et al. [25] illustrated that male gender corresponds to higher mental health related stigma scores. Furthermore, Mutiso et al. 
Table 1 Socio-demographic features of the first group (low stigma score) and the second group (high stigma score)

\begin{tabular}{|c|c|c|c|c|c|}
\hline \multirow{3}{*}{ Age (Mean \pm SD) } & \multicolumn{2}{|c|}{ Group I no.262 (45.72\%) } & \multicolumn{2}{|c|}{ Group II no.311 (54.28\%) } & \multirow[t]{2}{*}{$P$ value } \\
\hline & $29 \pm 6$ & & $24 \pm$ & & \\
\hline & No & $\%$ & No & $\%$ & \\
\hline \multicolumn{6}{|l|}{ Gender } \\
\hline Male & 143 & $54.58 \%$ & 144 & $46.30 \%$ & $0.048^{*}$ \\
\hline Female & 119 & $45.42 \%$ & 167 & $53.70 \%$ & \\
\hline Educational level & & & & & $0.0001^{* *}$ \\
\hline Illiterate & 13 & $4.96 \%$ & 37 & $11.90 \%$ & \\
\hline Less than high school & 27 & $10.31 \%$ & 53 & $17.04 \%$ & \\
\hline High school & 98 & $37.40 \%$ & 149 & $47.91 \%$ & \\
\hline College & 124 & $47.33 \%$ & 72 & $23.15 \%$ & \\
\hline Residency & & & & & $0.0001^{* *}$ \\
\hline Rural & 91 & $34.73 \%$ & 181 & $58.20 \%$ & \\
\hline Urban & 171 & $65.27 \%$ & 130 & $41.80 \%$ & \\
\hline Marital status & & & & & $0.0001^{* *}$ \\
\hline Single & 33 & $12.60 \%$ & 71 & $22.83 \%$ & \\
\hline Married & 137 & $52.29 \%$ & 109 & $35.05 \%$ & \\
\hline Divorced & 63 & $24.04 \%$ & 89 & $28.62 \%$ & \\
\hline Widow & 29 & $11.07 \%$ & 42 & $13.50 \%$ & \\
\hline Employment & & & & & $0.0001^{* *}$ \\
\hline Employed & 193 & $73.66 \%$ & 173 & $55.63 \%$ & \\
\hline Unemployed & 69 & $26.34 \%$ & 138 & $44.37 \%$ & \\
\hline Socio-economic status & & & & & $0.0001^{* *}$ \\
\hline Low class & 113 & $43.13 \%$ & 185 & $59.49 \%$ & \\
\hline Middle class & 91 & $34.73 \%$ & 87 & $27.97 \%$ & \\
\hline High class & 58 & $22.14 \%$ & 39 & $12.54 \%$ & \\
\hline
\end{tabular}

$P$ value $<0.05$ is considered statistically significant $\left({ }^{*}\right) . P$ value $<0.001$ is considered highly significant $\left({ }^{* *}\right)$

Table 2 Comparison between group I (low stigma score) and group II (high stigma score) regarding clinical features

\begin{tabular}{|c|c|c|c|c|c|}
\hline & \multicolumn{2}{|r|}{ GROUP (I) no. 262} & \multicolumn{2}{|c|}{ GROUP (II) no.311 } & $\frac{P \text { value }}{0.0001^{* *}}$ \\
\hline Mean $\pm S D$ & & $37 \pm 9$ & & & \\
\hline $\begin{array}{l}\text { Number of psychiatric hospital admission. } \\
\text { Mean } \pm \text { SD }\end{array}$ & & $2.1 \pm 0.3$ & & & $0.0001^{* *}$ \\
\hline Diagnosis & No. & $\%$ & No. & $\%$ & \\
\hline Schizophrenia & 17 & $6.49 \%$ & 35 & $11.25 \%$ & $0.007^{*}$ \\
\hline Other psychotic disorders & 8 & $3.05 \%$ & 23 & $7.40 \%$ & \\
\hline Bipolar affective disorder & 21 & $8.02 \%$ & 37 & $11.90 \%$ & \\
\hline Major depressive disorder & 103 & $39.31 \%$ & 97 & $31.19 \%$ & \\
\hline Anxiety disorders & 113 & $43.13 \%$ & 119 & $38.26 \%$ & \\
\hline
\end{tabular}

$P$ value $<0.05$ is considered statistically significant $\left({ }^{*}\right) . P$ value $<0.001$ is considered highly significant $\left({ }^{* *}\right)$

[26] reported that people's views regarding of mentally ill are the same for both women and men, and the differences in the findings may be related to cultural differences and how the society manages gender differences.
The findings of the current research support those of previous studies such as Hartini et al. [21] that higher mental stigma scores are more common among patients with low educational level (illiterate and less than high 
Table 3 Impact of psychiatric disorder stigma on group I and group II patients

\begin{tabular}{|c|c|c|c|c|c|}
\hline & \multicolumn{2}{|c|}{$\begin{array}{l}\text { Group (I) no } \\
262\end{array}$} & \multicolumn{2}{|c|}{$\begin{array}{l}\text { Group (II) no. } \\
311\end{array}$} & \multirow[t]{2}{*}{$P$ value } \\
\hline & No. & $\%$ & No. & $\%$ & \\
\hline Follow-up & & & & & $0.0001^{* *}$ \\
\hline Regular & 157 & $59.92 \%$ & 137 & $44.05 \%$ & \\
\hline Irregular & 105 & $40.08 \%$ & 174 & $55.95 \%$ & \\
\hline Adherence to medications & & & & & $0.001^{*}$ \\
\hline Adherent & 163 & $62.21 \%$ & 149 & $47.91 \%$ & \\
\hline Not adherent & 99 & $37.79 \%$ & 162 & $52.09 \%$ & \\
\hline Suicidal ideation or attempt & & & & & $0.0001^{* *}$ \\
\hline Yes & 57 & $21.76 \%$ & 141 & $45.34 \%$ & \\
\hline No & 205 & 78.24\% & 170 & $54.66 \%$ & \\
\hline
\end{tabular}

$P$ value $<0.05$ is considered statistically significant $(*) . P$ value $<0.001$ is considered highly significant (**). Follow-up visits were considered irregular if missed 3 or more follow-up visits in the past year. Adherence to medication is assessed by direct asking of the patient and their relatives about stopping or change of dose or timing of the medication during the follow-up visits

school) which is commonly associated with lower mental health literacy, and therefore has repercussions for the patient as he is not yet ready to make the right decisions what about to do when he/she has symptoms associated with mental illness. Through other means, patients with a lower educational level may have poor adaption methods or strategies to counter perceived stigmatization.

Our results revealed that patients living in rural areas (58.2\%) reported higher mental stigma scores than patients living in urban areas $(34.73 \%)$ which was evidenced by Townley et al. [27] who found that mental health stigma perceptions were more elevated in non-urban regions which can be attributed to several reasons such as fear of categorizing mentally ill patients into a small and closed community, low awareness levels, low education levels, lower socioeconomic status, cultural practices and beliefs, as well as the absence or inadequacy of mental health services. On the contrary, Mutiso et al. [26] mentioned that rural participants were more positive compared to those living in urban regions with regard to mental illness which could be attributed to the more demanding lifestyle in modern regions as well as fewer opportunities for mentally ill patients and finally the rapidly changing living conditions.

Regarding the marital status, the present study revealed that the number of single patients who recorded high stigma score $(22.83 \%)$ is more elevated than those who recorded low stigma score (12.6\%). While the number of married patients who recorded high stigma score $(35.05 \%)$ is lower than those who recorded low stigma score $(52.29 \%)$ which is in accordance with the results of Hartini et al. [21] who stated that married participants have greater tolerance toward mental illness than divorced or single subjects. However, Szczesniak [28] and Kalisova [29] could not detect any significant effect of marital status on the level of self-stigma.

The results of the current study demonstrated that the pervasiveness of elevated perceived stigma is high among unemployed participants (44.37\%) than employed ones (26.34\%) in parallel with the results of Kalisova [29] who found that unemployed patients have higher levels of self-stigmatization than employed patients. This can be attributed to the multiple discrimination that can impact job opportunities and help seeking among the mentally unemployed. In contrast, unemployment may result in a novel social identity which is stigmatized and correlated with impaired well-being [30].

In parallel with the study of Hartini et al. [21], our findings revealed that patients with low socioeconomic class

Table 4 Regression analysis to determine risk factors predicting stigma in mental illness

\begin{tabular}{|c|c|c|c|c|c|c|c|c|}
\hline & & $R$ & $R$ square & $\begin{array}{l}\text { Unstandardized } \\
\text { coefficient }\end{array}$ & $\begin{array}{l}\text { Standardized } \\
\text { coefficient }\end{array}$ & $t$ & $f$ & sign \\
\hline & Age & 0.059 & 0.003 & 0.099 & 0.059 & 0.448 & 0.201 & 0.656 \\
\hline & Gender & 0.115 & 0.013 & 0.26 & 0.115 & 0.883 & 0.78 & 0.381 \\
\hline & Level of education & 0.236 & 0.082 & 0.27 & 0.236 & 2.275 & 10.436 & $0.03^{*}$ \\
\hline & Residence & 0.064 & 0.004 & 0.049 & 0.064 & 0.485 & 0.235 & 0.63 \\
\hline & Marital status & 0.068 & 0.005 & 0.046 & 0.068 & 0.491 & 0.238 & 0.611 \\
\hline \multirow{5}{*}{$\begin{array}{l}\text { Stigma scale } \\
\text { score }\end{array}$} & Employment & 0.042 & 0.001 & 0.086 & 0.042 & 0.412 & 0.195 & 0.354 \\
\hline & Socioeconomic status & 0.234 & 0.014 & 0.074 & 0.047 & 0.374 & 0.217 & 0.211 \\
\hline & Duration of illness & 0.252 & 0.091 & 0.225 & 0.252 & 2.415 & 5.831 & $0.019^{*}$ \\
\hline & Number of hospital admissions & 0.227 & 0.077 & 0.287 & 0.227 & 2.193 & 4.809 & $0.032^{*}$ \\
\hline & Diagnosis & 0.277 & 0.107 & 0.412 & 0.277 & 2.638 & 6.959 & $0.01^{*}$ \\
\hline
\end{tabular}

$P$ value $<0.05$ is considered statistically significant $\left(^{*}\right)$ 
recorded high stigma scores $(59.49 \%)$ more frequently than those recorded low stigma scores (43.13\%), which is in contrast to the results of Knesebeck [31] who demonstrated that people with low socioeconomic class to do not seem to experience a double public stigma with regard to emotional reactions, stereotypes, as well as desire for social distance compared to those of high socioeconomic class.

In our study, we found a positive association between longer duration of psychiatric illness $(43 \pm 8)$ and higher stigma scores in comparison to shorter duration of psychiatric illness $(37 \pm 9)$ recording low stigma scores which can be attributed to higher stigma scores. Since it is more common in psychotic disorders, because it is a chronic long standing disorder. Similar results were obtained by Szczesniak [28] who stated that disease duration was the only clinical parameter displaying a marked positive association with stigma internalization. In contrast, Kinson [24] found that discrimination as well as stigmatization are highly common among patients with first episode psychosis which may be related to different demographic variables, and level of functioning.

The present study revealed that mental stigma has a significant positive correlation with the number of psychiatric hospital admission which aligns with the findings of Xu et al. [32] and Michaela et al. [33] who reported that the self-stigma has been found to be significantly correlated with the number of hospitalizations as patients who have experienced more hospital admission are more likely to be discriminated besides experiencing more disorder attacks. Opposite results have been reported by Puamau [34] who mentioned that mental stigma is more common in the first psychiatric hospital admission.

In this research we found that patients with schizophrenia and other psychotic disorders who recorded high stigma scores (11.25\% and $7.40 \%$ respectively) are more frequent than those who recorded low scores $(6.49 \%$ and $3.05 \%$ respectively) which is compatible with results of Holubova [35] who stated that the individuals with neurotic spectrum disorders or depression had a lower degree of self-stigma compared to those with schizophrenia spectrum disorders. However, contrary results obtained by Loughman [36] denote that genetic and other biological aspects seem to have dual effects with regard to the stigma of mental disorders.

Our study revealed that patients with irregular psychiatric follow-up and those who did not adhere to medications got significantly high stigma scores $(55.95 \%$ and $52.09 \%$ respectively). This is in agreement with Chaudhari [37] who illustrated that $52 \%$ of the psychiatric patients were low adherent to psychiatric medication as patients experience a sense of shame and stigma related to illness and treatment. In addition, Kearns
[38] concluded that stigmatization of mental illness and attitudes toward seeking help are identified as barriers to obtaining professional aid. In this research, patients with high mental stigma scores showed a high frequency of suicidal thoughts or attempts (45.34\%) similar to the results of Kucukalic [17] who stated that stigma as well as suicide are linked in two directions which means that suicide may result in stigma, nonetheless, stigma can also result in suicidal thoughts.

\section{Strengths}

There is limited research demonstrating the risk factors and the impact of mental stigma in our locality. The patients enrolled in the current were randomly chosen from the psychiatric clinic and a variety of other clinics. The range of the participants' gender as well as age and diagnoses of the psychiatric disorder included indicate that we enrolled a wide range of users of mental health services.

\section{Limitations of the study}

The current study has a number of limitations; particularly that causality of the described relations cannot be explained. Sample size is small, and therefore, the research findings, particularly the results of the regression analysis, cannot be generalized. Some modifications can be made to the questionnaires such as adding multiple levels of fatigue and motivation of subjects.

\section{Recommendations}

There is an urgent need to confront stigma and thus mentally ill can be estimated as equal members of their communities. Then, development of psycho-educational as well as internet programs that concentrate on eliminating self-stigma. There is also a need for campaigns to improve mental health literacy as well as counter stigmatizing attitudes that may have beneficial effects in eliminating the desire for social distancing from mentally ill patients. The current study requires further assessment in larger groups of patients in distinct diagnostic cohorts to understand psychiatric stigma as well as its consequences.

\section{Conclusions}

We conclude that mental stigma is more common in patients who are young, female, single, unemployed, living in rural areas and have low educational and socioeconomic level. Mental stigma is positively correlated with the psychiatric disorder duration, frequency of psychiatric hospital admission and diagnosis of psychotic disorder. Mental stigma may negatively affect psychiatric patient's regular follow-up, adherence to medications and stimulation of suicidal thoughts or attempts. 


\section{Abbreviation}

DSM-5: Diagnostic and Statistical Manual of Mental Disorders, Fifth Edition.

\section{Acknowledgements}

We are expressing our cordial gratitude to the appreciated effort and time given by all patients who participated in this study.

\section{Authors' contributions}

TAS: The idea of the research. Recruiting and interviewing the patients, applying the questionnaires and sample collection. MMA: Contribution in research idea selection, sampling planning, statistical analysis. SH: Contribution in research idea selection, applying the questionnaires, manuscript writing, revising the references and paper submission. All authors read and approved the final manuscript.

\section{Funding}

The authors of this manuscript declare that no funding bodies were involved in sponsoring or funding this research.

\section{Availability of data and materials}

The data sets used and/or analyzed during the current study are available from the corresponding author on reasonable request.

\section{Declarations}

\section{Ethics approval and consent to participate}

The study protocol was approved by the Medical Research Ethics Committee of faculty of Medicine, Sohag University under IBM Registration Number: Soh-Med-19-04-08. Participants were constructed about the study as well as its objectives, and then invited to participate. Written informed consent was obtained from patients for participation in this study.

\section{Consent for publication}

Consent for publication was obtained.

\section{Competing interests}

All authors declare that they have no competing interests.

\section{Author details}

${ }^{1}$ Department of Neuropsychiatry, Sohag Faculty of Medicine, Sohag University, Sohag, Egypt. ${ }^{2}$ Department of Public Health and Community Medicine, Sohag Faculty of Medicine, Sohag University, Sohag, Egypt.

Received: 15 July 2021 Accepted: 19 October 2021

Published online: 30 October 2021

\section{References}

1. Reavley NJ, Jorm AF. Recognition of mental disorders and beliefs about treatment and outcome: findings from an Australian national survey of mental health literacy and stigma. Aust N Z J Psychiatry. 2011:45(11):947-56

2. Corrigan PW, Waston AC. Understanding the impact of stigma on people with mental illness. World Psychiatry. 2002;1(1):16-20.

3. Henderson C, Thornicroft G. Stigma and discrimination in mental illness: time to change. Lancet. 2009:373:1928-30.

4. Abdullah T, Brown TL. Mental illness stigma and ethnocultural beliefs, values, and norms: an integrative review. Clin Psychol Rev. 2011;31:934-48.

5. Dovidio JF, Major B, Crocker J. Stigma: introduction and overview. In: Heatherton TF, Kleck RE, Hebl MR, Hull JG, editors. The social psychology of stigma. New York: Guilford Press; 2000. p. 1-28.

6. Lucksted A, Drapalski AL. Self-stigma regarding mental illness: definition, impact, and relationship to societal stigma. Psychiatr Rehabil J. 2015;38(2):99-102.

7. Yanos PT, Roe D, Lysaker PH. The impact of illness identity on recovery from severe mental illness. Am J Psychiatr Rehabil. 2010;13(2):73-93.

8. Ociskova M, Prasko J, Kamaradova D, Grambal A, Sigmundova Z. Individual correlates of self-stigma in patients with anxiety disorders with and without comorbidities. Neuropsychiatr Dis Treat. 2015:11:1767-79.
9. Ociskova M, Prasko J, Kamaradova D, Grambal A, Sigmundova Z. Individual correlates of self-stigma in patients with anxiety disorders with and without comorbidities. Neuropsychiatr Dis Treat. 2015;2015(11):1767-79.

10. Rusch N, Angermeyer MC, Corrigan PW. Mental illness stigma: concepts, consequences and initiatives to reduce stigma. Eur Psychiatry. 2005;20(8):529-39.

11. Gerlinger G, Hauser M, De Hert M, Lacluyse K, Wampers M, Correll CU. Personal stigma in schizophrenia spectrum disorders: a systematic review of prevalence rates, correlates, impact and interventions. World Psychiatry. 2013;12(2):155-64.

12. Zhang Z, Sun K, Jatchavala C, Koh J, Chia Y, Bose J, Li Z, Tan W, Wang S, Chu W, Wang J, Tran B, Ho R. Overview of stigma against psychiatric illnesses and advancements of anti-stigma activities in six Asian societies. Int J Environ Res Public Health. 2019;17(1):280. https://doi.org/10.3390/ ijerph17010280.

13. Holubova M, Prasko J, Latalova K, Ociskova M, Grambal A, Kamaradova D, et al. Are self-stigma, quality of life and clinical data interrelated in schizophrenia spectrum patients? A cross-sectional outpatient study. Patient Prefer Adherence. 2016;10:265-74.

14. Sukhera J, Miller K, Scerbo C, Milne A, Lim R, Watling C. Implicit stigma recognition and management for health professionals. Acad Psychiatry. 2019:44(1):59-63.

15. Oexle N, Rusch N. Stigma-risk factor and consequence of suicidal behavior: implications for suicide prevention. Nervenarzt. 2017;89(7):779-83.

16. Gronholm PC, Thornicroft G, Laurens KR, Evans-Lacko S. Mental healthrelated stigma and pathways to care for people at risk of psychotic disorders or experiencing first-episode psychosis: a systematic review. Psychol Med. 2017;47(11):1867-79.

17. Kucukalic S, Kucukalic A. Stigma and suicide. Psychiatr Danub. 2017;29(Suppl 5):895-9.

18. Dalky HF. Perception and coping with stigma of mental illness: Arab families' perspectives. Issues Ment Health Nurs. 2012;33(7):486-91.

19. King M, Dinos S, Show J, Watson R, Stevens S, Passetti F, et al. The Stigma Scale: development of a standardized measure of the stigma of mental illness. Br J Psychiatry. 2007;190:248-54.

20. World Health Organization. The world health report, approach to mental health. Geneva: WHO; 2001

21. Hartini N, Fardana NA, Ariana AD, Wardana ND. Stigma toward people with mental health problems in Indonesia. Psychol Res Behav Manag 2018:31(11):535-41.

22. Zaske H, Linden M, Degner D, Jockers-Scherubl M, Sand K, Schmitt A, et al. Stigma experiences and perceived stigma in patients with firstepisode schizophrenia in the course of 1 year after their first in-patient treatment. Eur Arch Psychiatry Clin Neurosci. 2018;269(4):459-68.

23. Boge K, Zieger A, Mungee A, Tandon A, Fuchs LM, Schomerus G, et al. Perceived stigmatization and discrimination of people with mental illness: a survey-based study of the general population in five metropolitan cities in India. Indian J Psychiatry. 2018;60(1):24-31.

24. Kinson RM, Hon C, Lee H, Abdin EB, Verma S. Stigma and discrimination in individuals with first episode psychosis; one year after first contact with psychiatric services. Psychiatry Res. 2018;270:298-305.

25. Gierk B, Lowe B, Murray AM, Kohlmann S. Assessment of perceived mental health-related stigma: the Stigma-9 Questionnaire (STIG-9). Psychiatry Res. 2018;270:822-30.

26. Mutiso VN, Musyimi CW, Tomita A, Loeffen L, Burns JK, et al. Epidemiological patterns of mental disorders and stigma in a community household survey in urban slum and rural settings in Kenya. Int I Soc Psychiatry. 2018:64(2):120-9.

27. Townley G, Brusilovskiy E, Salzer MS. Urban and non-urban differences in community living and participation among individuals with serious mental illnesses. Soc Sci Med. 2017;177:223-30.

28. Szczesniak D, Kobyłko A, Wojciechowska I, Klapcinski M, Rymaszewska J. Internalized stigma and its correlates among patients with severe mental illness. Neuropsychiatr Dis Treat. 2018;14:2599-608.

29. Kalisova L, Michalec J, Hadjipapanicolaou D, Raboch J. Factors influencing the level of self-stigmatisation in people with mental illness. Int J Soc Psychiatry. 2018;64(4):374-80

30. Donnell ATO, Corrigan F, Gallagher S. The impact of anticipated stigma on psychological and physical health problems in the unemployed group. Front Psychol. 2015;6:1-8. 
31. Knesebeck OVD, Kofahl C, Makowski AC. Differences in depression stigma towards ethnic and socio-economic groups in Germany-exploring the hypothesis of double stigma. J Affect Disord. 2017;208:82-6.

32. Xu Z, Lay B, Oexle N, Drack T, Bleiker M, Lengler S, et al. Involuntary psychiatric hospitalisation, stigma stress and recovery: a 2-year study. Epidemiol Psychiatr Sci. 2018;31:1-8.

33. Holubova M, Prasko J, Matousek S, Latalova K, Marackova M, Vrbova K, et al. Comparison of self-stigma and quality of life in patients with depressive disorders and schizophrenia spectrum disorders-a cross-sectional study. Neuropsychiatr Dis Treat. 2016;12:3021-30.

34. Puamau ES. Utilisation review of first admissions in 2002: St Giles Psychiatric Hospital, Suva, Fiji. Pac Health Dialog. 2006;13(2):79-87.

35. Holubova M, Prasko J, Ociskova M, Vanek J, Slepecky M, Zatkova M, et al. Three diagnostic psychiatric subgroups in comparison to self-stigma, quality of life, disorder severity and coping management cross-sectional outpatient study. Neuro Endocrinol Lett. 2018;39(4):331-41.
36. Loughman A, Haslam N. Neuroscientific explanations and the stigma of mental disorder: a meta-analytic study. Cogn Res Princ Implic. 2018;3(1):1-12.

37. Chaudhari B, Saldanha D, Kadiani A, Shahani R. Evaluation of treatment adherence in outpatients with schizophrenia. Ind Psychiatry J. 2017;26(2):215-22.

38. Kearns M, Muldoon OT, Msetfi RM, Surgenor PWG. The impact of community-based mental health service provision on stigma and attitudes towards professional help-seeking. J Ment Health. 2018;20:1-7.

\section{Publisher's Note}

Springer Nature remains neutral with regard to jurisdictional claims in published maps and institutional affiliations.

\section{Submit your manuscript to a SpringerOpen ${ }^{\circ}$ journal and benefit from:}

- Convenient online submission

- Rigorous peer review

- Open access: articles freely available online

- High visibility within the field

- Retaining the copyright to your article

Submit your next manuscript at $\gg$ springeropen.com 